\title{
Histopathology findings in anaphylaxis shock
}

\author{
Adriana Grigoraș ${ }^{1,2}$, Anton Knieling ${ }^{*}, 1,2$, Laura Knieling ${ }^{1,2}$, Diana Bulgaru Iliescu,2, \\ Simona Eliza Giușcă ${ }^{1}$, Elena Roxana Avădănei ${ }^{1}$, Irina-Draga Căruntu ${ }^{1}$, Cornelia \\ Amălinei ${ }^{1,2}$
}

1 "Grigore T. Popa" University of Medicine and Pharmacy, lasi, ${ }^{2}$ Institute of Legal Medicine, lasi, Romania

\begin{abstract}
Known by more than two centuries as cells described by Paul Erlich, mast cells still remain the most actively involved cells in allergy pathogeny, including its most severe manifestation, anaphylaxis shock. Brutal mast cells degranulation, due to contact with an allergen, is followed by the release of preformed or newly synthesized factors which would be associated to an entire spectrum of clinical manifestations that may eventually be lethal. Within this context, we present the case of a man who died by anaphylaxis shock after exposure to a great number of bee bites. Standard microscopy and anti-tryptase immunohistochemistry, revealed in necroptic specimens, edema, vascular congestion, extensive hemorrhages, and an increased number of perivascular mast cells within the inflammatory reaction in lesional skin, tongue base, epiglottis, larynx, extended more than subepithelial location up to periglandular and perimuscular locations. The histopathological picture provides a better understanding of clinical symptoms that lead to death in such cases.
\end{abstract}

Keywords: mast cells, anaphylaxis shock, anti-mast cell tryptase antibody

\section{Introduction}

Anaphylaxis is a medical urgency, with vital potential, which needs immediate recognition and intervention. The most frequent organs involved are skin (80-90\%), respiratory $(70 \%)$, cardiovascular $(10-45 \%)$, and gastrointestinal systems (30-45\%), characteristic symptoms being bronchospasm, glottal edema, pruritus, and hypotension [1].

Anaphylactic shock is manifested as a brutal response of the organism to the contact with trigger substances (insects venom, food, or drugs) secondary to inflammatory mediators and cytokines release, mainly due to mast cells degranulation, in a type I allergic reaction, mediated by strongly expressed surface FceRI $[2,3,4]$.

Received: March 2015; Accepted after review: March 2015; Published: March 2015.

${ }^{*}$ Corresponding author: Knieling Anton, MD, PhD, Institute of Legal Medicine, lasi, "Grigore T. Popa" University of Medicine and Pharmacy lasi, Romania. Email: tony knieling@yahoo.com
Hymenoptera family insects venom, including bees and wasps, generally determine only local reactions associated to the bite site [4]. In $3.5 \%$ of cases these reactions may have a lethal potential, as 20 people are reported as dying in Germany annually due to anaphylaxis reaction development by lgE-mediated reaction following one or several bites [5].

\section{Case report}

We present the case of a 38 year-old man, unknown with previous allergic manifestations, who deceased in a short period after approximately 144 bee bites. The incident had been in a relatively remote location preventing the appropriate medical assistance.

Necroptic examination has been associated to collection of tissue specimens for microscopy. Paraffin-embedding followed by routine, hematoxylin-eosin (HE) and Verhoeff's van Gieson stainings and immunohisto- 
chemistry using anti-mast cell tryptase $A b$ (clone 10D11, Novocastra) have been performed.

Numerous bee bites on areas unprotected by clothes, edema, and hyperemia in larynx mucosa, base of the tongue, and epiglottis, and hemorrhage in periesophageal tissues were the main necropsy gross findings. Supplementary, cerebral, lung, and renal edema have been noticed. Other background features have been incipient coronary arteries atherosclerosis and subepicardial ischemic myocardial fibrosis.

Routine microscopy confirmed the cerebral edema, the meningo-cerebral congestion associated to focal subarachnoid hemorrhage. Lung parenchyma revealed areas of serous edema associated to alveolar and interstitial hemorrhages. Periesophageal tissues showed areas of hemorrhage (Figure 1 and Figure 2).

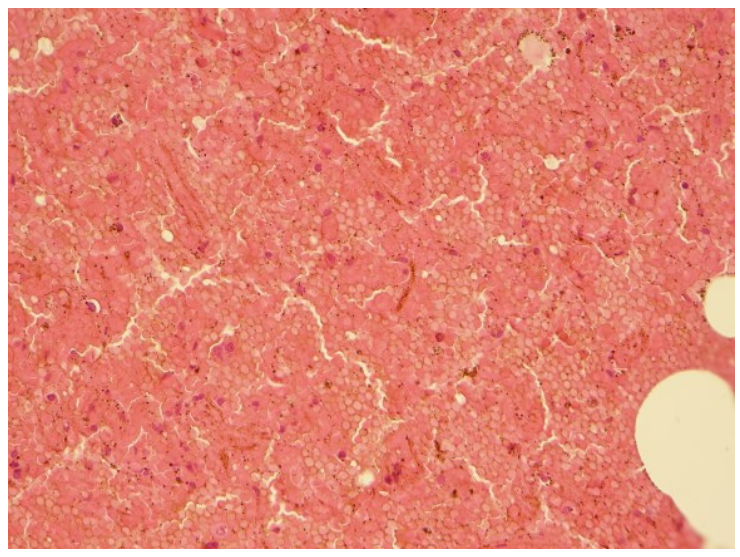

Fig. 1. Alveolar and interstitial hemorrhages (HE, $\mathrm{x} 100)$

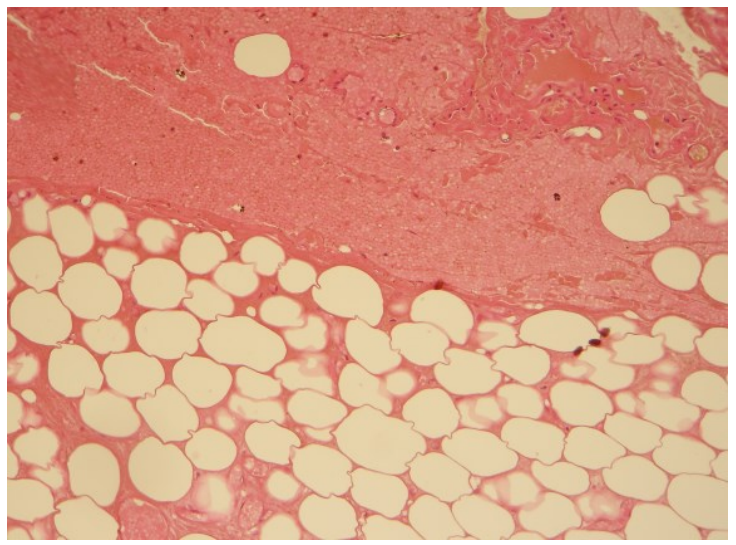

Fig. 2. Periesophageal hemorrhage (HE, x40)
The base of the tongue, glottis, and larynx showed edema and dissociation of connective tissue fibers with evidence of elastic fibers fragmentation (Figure 3 and Figure 4).

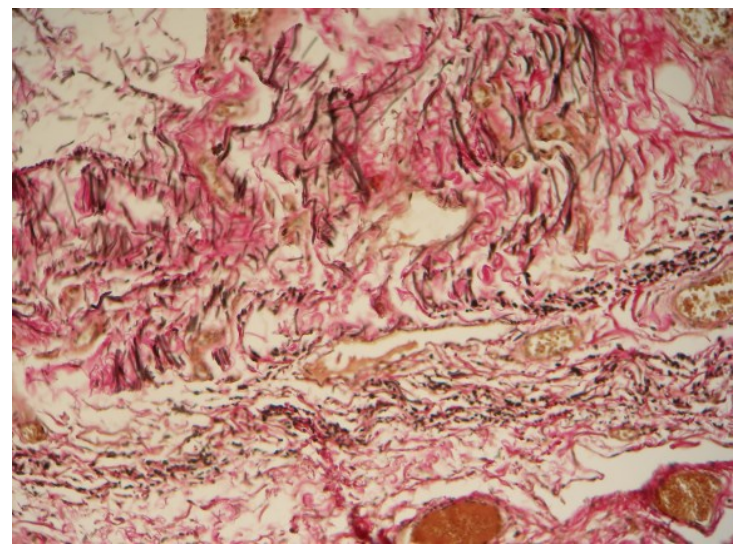

Fig. 3. Dissociation and rupture of elastic fibers in larynx mucosa (Verhoeff's van Gieson, x100)

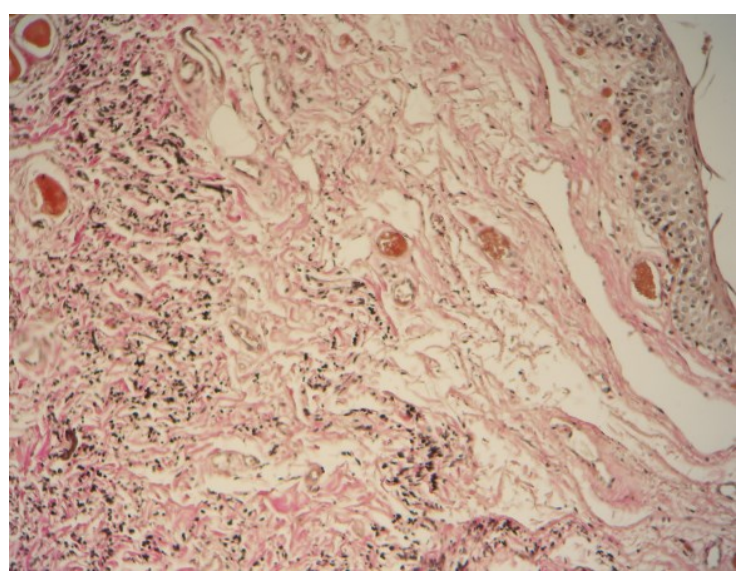

Fig. 4. Elastic fibers fragmentation in lingual mucosa (Verhoeff's van Gieson, x100)

Marked congestion has been noticed, in association with perivascular microhemorrhages in striated muscular fibers. Moreover, inflammatory perivascular aggregates, composed mainly of mononuclear cells have been mainly observed in the lamina propria (Figure 5).

Collected cutaneous fragments corresponding to bee bites revealed focal intraepithelial vacuolization and epidermal layers detachment in spinosum or granulosum layers, focal papillary dermal edema, congestion, and discrete perivascular inflammatory infiltrate (Figure 6). 


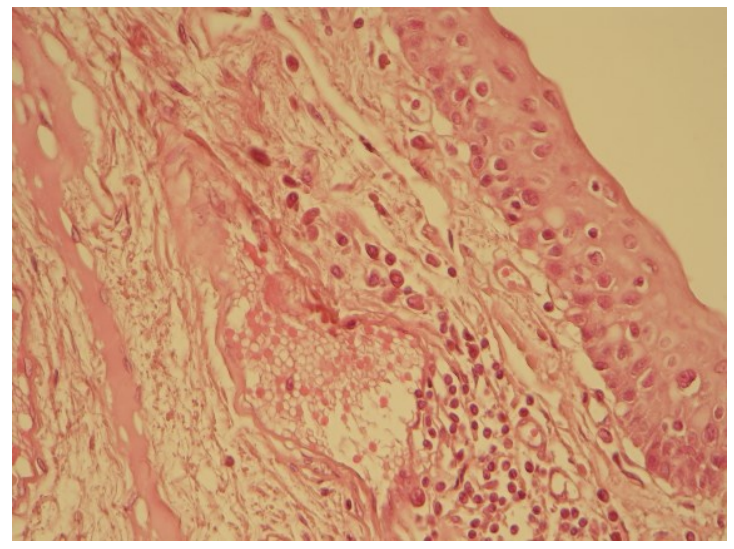

Fig. 5. Inflammatory perivascular microaggregates in lingual mucosa (HE, x200)

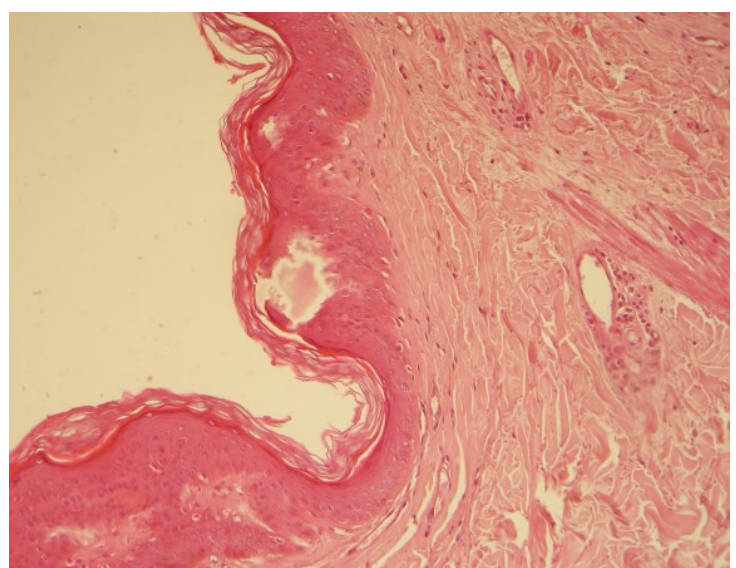

Fig. 6. Focal intraepidermal vacuolization in injured areas (HE, x100)

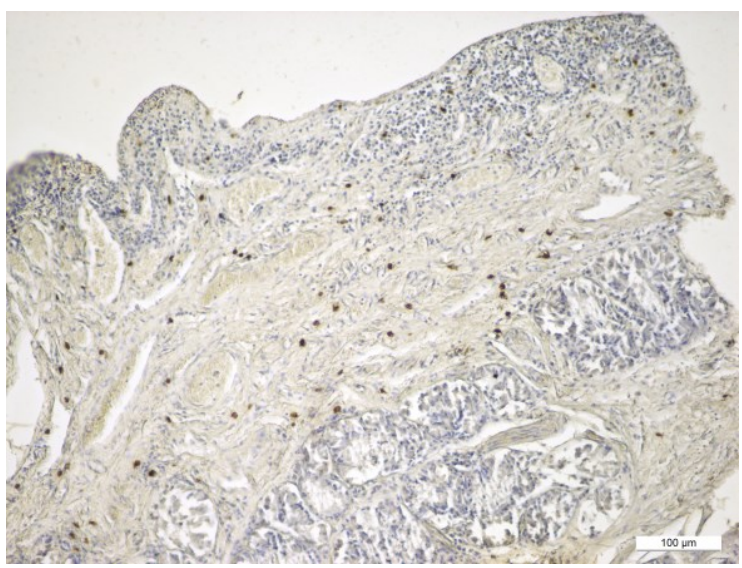

Fig. 7. Lingual lamina propria mast cells perivascular and periglandular infiltrate (anti-mast cell tryptase $A b, x 40)$.

Anti-mast cell tryptase antibodies allowed us the semi-quantitative evaluation of mast cells within perivascular inflammatory infiltrates noticed in airways mucosa and in superficial dermis. Interestingly, periglandular areas and deeper muscular connective capsules also revealed an increased number of mast cells (Figures 7-9).

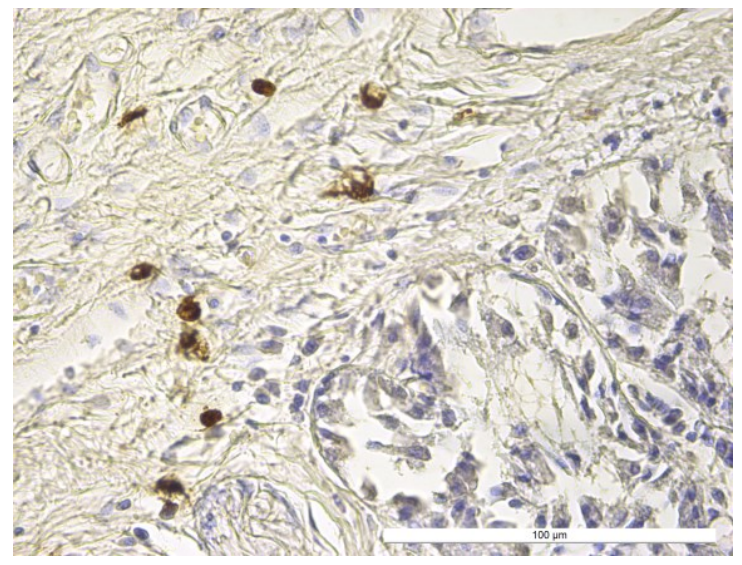

Fig. 8. Lingual lamina propria mast cells (anti-mast cell tryptase Ab, x200)

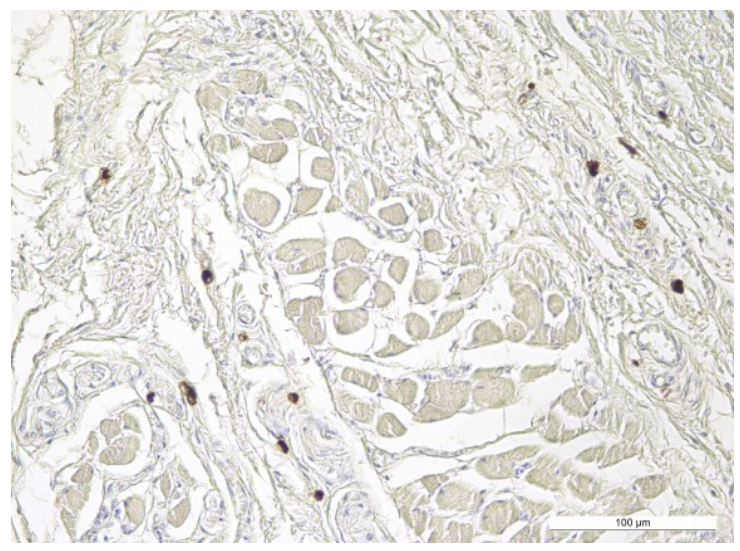

Fig. 9. Laryngeal perimuscular mast cells infiltrate (anti-mast cell tryptase Ab, x100)

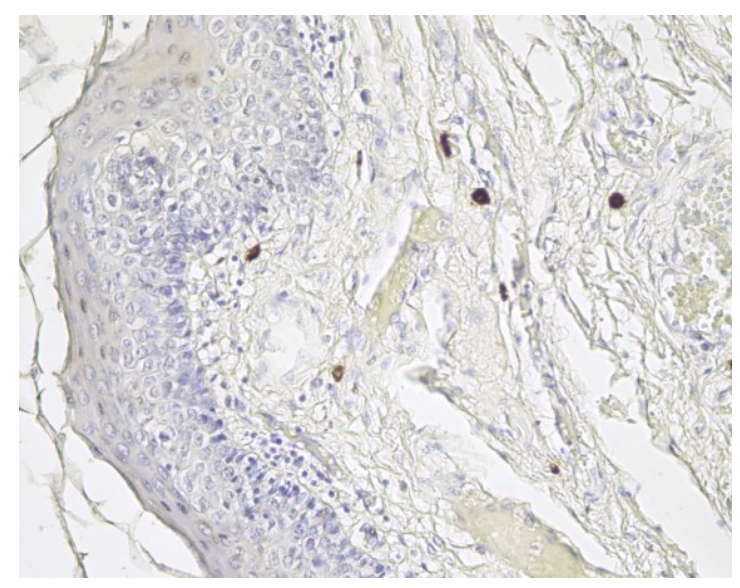

Fig. 10. Intradermal mast cells infiltrate (anti-mast cell tryptase Ab, x200) 
As a modality of dermal distribution, capillary subepithelial plexus showed more mast cells compared to larger vessels of the reticular dermis or periannexial (Figure 10).

\section{Discussions}

The term „anaphylaxis” has been firstly used in 1902, by Portier and Richet, to describe a dog death following a second vaccine containing sea anemone, derived from Greek "ana” (against) and "phylaxis" (protection) [6].

Beside the pivotal role in allergic reactions by rapid release of active biological substances, mast cells, described by Paul Erlich more than two centuries ago [7] have multifunctional attributes in various immune mechanisms [8].

Due to their distribution in perivascular areas in connective tissues connected to the environment, such as skin, respiratory or gastrointestinal mucosa, they are considered as "guardians".

Without any distinctive morphological characteristics, mast cells are identified due to their property of metachromasia in Blue toluidine staining. There are two main categories of mast cells, according to their type of serine protease, tryptase, a trypsin-like enzyme, and chymase, a chymotrypsin-like enzyme, tryptase-positive mast cells $\left(\mathrm{MC}_{\mathrm{T}}\right)$, which contain tryptase but not chymase, and the tryptase- and chymase-positive mast cells $\left(\mathrm{MC}_{\mathrm{TC}}\right)$, which contain both enzymes $[9,10]$. Supplementary, mast cells granules contain sulphated proteoglycans (heparin in connective tissue mast cells or chondroitin sulphate in mucosal mast cells), histamine, serine proteases (cathepsin G, granzyme B, carboxypeptidase A3), Plasminogen activating factor, Platelet Activating Factor, eosinophils and neutrophils chemotactic factors, $\beta$ glucuronidase, aryl-sulfatase, and hexosaminidase [10]. Following activation, they may produce other mediators such as: tumor necrosis factor $\alpha$ (TNF- $\alpha$ ), IL-4, IL-3, IL-5, IL-6, IL-8, IL-16, growth factors (GM-CSF, VEGF), prostaglandin D2 (PGD2), thromboxanes, leukotrienes C (LTC4), D (LTD4), and E (LTE4), the latter being responsible, in association with histamine, of bronchospasms or respiratory airways smooth muscle contraction $[10,11]$.

Mast cells are critical for allergic reactions where the stimulus is immunoglobulin $E(\lg E)$ and specific antigen, as their surface express High affinity receptors FceR1. Their activation is enhanced by basophils intervention in later stages of the allergic phenomena.

Numerous ligands, such as immune complexes, chemokines, cytokines, sphingosine-1-phosphate (S1P), SCF, adenosine, C3A, PAMPs are able to potentiate FceRI- mediated activation or to directly stimulate the release of various mediators in FceRI- independent manner [12].

Experimental models have revealed mast cells involvement in various immune mechanisms, in carcinogenesis, and in cardiovascular pathology [2] beside their characteristic role in type I allergic reactions, including the most severe type - anaphylactic shock due to their strong expression of FceRI [13-15].

FceRI belong to immunoglobulin type receptors, able to bind IgE produced by activated $B$ cells following a contact with an allergen. Their activation results in various intra-cellular effects, such as protein phosphorylation, calcium ions intracellular mobilization, and activator factors transcription, resulting mast cell degranulation and the induction of newly formed lipid mediators release $[16,17]$.

Our finding of elastin fibers destruction could be supported by previous reports of a selective in vivo release of elastase in lgEmediated human late phase allergic reactions, possibly related in degree to earlier mast cell activation [7].

Generally, anaphylactic reactions are characterized by an explosive dynamic of events, taking 3-4 minutes, with clinical picture depending on the allergen entrance site, manifested by sudden onset of epiglottic and laryngeal edema added to cutaneous areas, as venom sites of penetration in the presented case.

Among the mast cells activation factors are insects' venom which is known to be responsible for severe allergic reactions, followed by death [18], as we have seen in the presented case. 
Bees' venom is a complex product able to induce cardiovascular, respiratory, and nervous anomalies, with hypotension, bronchospasm, edema, convulsions or paralysis as a result of the release of stored and newly synthesized active substances from mast cells and basophils, causing individual death, as in this case.

The lack of immediate specialized medical assistance had been an aggravating factor in our case, beside the great number of bites [5], and consequently a greater venom quantity, considering also that the bee bites have been mainly distributed in certain noncovered cutaneous areas. Microscopy revealed nonspecific local skin changes or respiratory changes, as pulmonary microhemorrhages or edema and congestive vessels and also perivascular inflammatory microfoci. Immunohistochemistry had confirmed an increased number of mast cells in the mucosa

\section{References}

1. Simons FE. World Allergy Organization survey on global availability of essentials for the assessment and management of anaphylaxis by allergy-immunology specialists in health care settings. Ann Allergy Asthma Immunol 2010; 104(5):405-412.

2. da Silva EZ, Jamur MC, Oliver C. Mast cell function: a new vision of an old cell. J Histochem Cytochem 2014; 62(10):698-738.

3. Bilò MB. Anaphylaxis caused by Hymenoptera stings: from epidemiology to treatment. Allergy 2011; 66(95): 35-37.

4. Boden SR, Wesley Burks A. Anaphylaxis: a history with emphasis on food allergy. Immunol Rev 2011; 242(1):247-257.

5. Przybilla B, Ruëff F. Insect stings: clinical features and management. Dtsch Arztebl Int 2012; 109(13):238-248.

6. Ring J, Behrendt $\mathrm{H}$, de Weck A. History and classification of anaphylaxis. Chem Immunol Allergy 2010; 95:1-11.

7. Zweiman B, Kucich U, Shalit M, et al. Release of lactoferrin and elastase in human allergic skin reactions. J Immunol. 1990; 144(10):39533960.

8. Galli SJ, Borregaard N, Wynn TA. Phenotypic and functional plasticity of cells of innate immunity: macrophages, mast cells and neutrophils. Nat Immunol 2011; 12:1035-1044. of the base of the tongue and of laryngeal wall, supporting the severe anaphylaxis that lead to death.

\section{Conclusions}

Patient death followed the anaphylactic shock developed due to numerous bee bites, in the lack of immediate specialized medical assistance, and immunohistochemistry showed an increased number of mast cells in skin and respiratory mucosa, associated to vascular congestion, edema, and hemorrhages, confirming the tissular allergic phenomena as an initiator factor.

The histopathological picture revealed by extensive collection of specimens provides a better understanding of clinical symptoms spectra potentially lethal in such cases.

9. e Cássia Campos MR, Toso VD, de Souza DA $\mathrm{Jr}$, et al. Differential effects of chemoattractants on mast cell recruitment in vivo. Cell Immunol 2014; 289:86-90.

10. Ross MC, Pawlina W. Histology - a text and atlas with correlated cell and molecular biology. $6^{\text {th }}$ edition. Philadelphia: Lippincott Williams \& Wilkins, 2011.

11. Caughey $\mathrm{GH}$. Mast cell proteases as protective and inflammatory mediators. Adv Exp Med Biol 2011; 716:212-234.

12. Gilfillan A, Tkaczyk C. Integrated signaling pathways for mast-cell activation. Nat Rev Immunol 2006; 6:218-230.

13. Yamaguchi M, Lantz CS, Oettgen HC, et al. IgE enhances mouse mast cell Fc (epsilon) RI expression in vitro and in vivo: evidence for a novel amplification mechanism in lgEdependent reactions. J Exp Med 1997; 185:663-672.

14. Smallheer BA. Bee and wasp stings: reactions and anaphylaxis. Crit Care Nurs Clin North Am 2013; 25(2):151-164.

15. Lee JK, Vadas P. Anaphylaxis: mechanisms and management. Clin Exp Allergy 2011; 41(7):923-938.

16. Weller CL, Collington SJ, Williams T, Lamb JR. Mast cells in health and disease. Clin Sci (Lond) 2011; 120:473-484. 
17. Tkaczyk C, Jensen BM, Iwaki S, Gilfillan AM. Adaptive and innate immune reactions regulating mast cell activation: from receptormediated signaling to responses. Immunol Allergy Clin North Am 2006; 26:427-450.
18. Shen Y, Li L, Grant J, et al. Anaphylactic deaths in Maryland (United States) and Shanghai (China): a review of forensic autopsy cases from 2004 to 2006. Forensic Sci Int 2009; 186(1-3):1-5. 